\title{
Comment
}

\section{Determining what should be included in a publicly funded health care system: reflecting on 'Individual responsibility for what? A conceptual framework for exploring the suitability of private financing in a publicly funded health-care system"}

\author{
MARK STABILE* \\ Department of Economics, Sciences Po, France
}

Health care cost growth exceeded growth in GDP over the past decade for the majority of countries in the OECD (Stabile et al., 2013). In response to these increased costs policy makers concerned with balancing the quality of the public service and the sustainability of the public purse have a limited set of options to deploy including tax increases, deficit financing, cost containment and cost shifting. Within the domains of cost containment and cost shifting, policy makers must concern themselves with defining the boundaries of the publicly funded benefit and deciding how to best manage, through any regulation or taxation, those items that are not funded publicly.

It is in this context that 'Individual responsibility for what? A conceptual framework for exploring the suitability of private financing in a publicly funded health-care system' by Tinghog, Carlsson and Lyttkens, provides both careful consideration and an interesting set of options for determining what is privately (and hence publicly) funded. No publicly financed health care system covers every conceivable health care service fully within the public basket. The role of private financing (both through insurance and out of pocket) for those services not covered publicly then generally falls within four broad categories: substitute, complementary service, complementary user charges, and supplementary (Thomson and Mossialos, 2009). Many systems have elements of several of these categories at play at the same time. Substitutive insurance and financing generally refers to

\footnotetext{
*Correspondence to: Mark Stabile, Department of Economics, Sciences Po, 28 Rue des Saints-Pères, 75007 Paris, France. Email: Mark.stabile@sciencespo.fr
} 
private insurance for people who are not covered, or who have opted out of the public system (e.g. Germany). Complementary coverage or financing refers to private financing for services not covered with the public system such as dental care or pharmaceutical coverage (e.g. Canada). Complementary charges refers payment of, or private insurance for, user fees that are in addition to the amounts covered by the public system (e.g. France). Finally, supplemental insurance or financing refers to the private purchase or insurance of services that are also covered within the public system (e.g. United Kingdom).

The authors of the paper begin by making an essential point that policy makers within a publicly funded health care system are making decisions all the time about which services to include and which to exclude often across many of these margins. For example, a service could be covered but an additional user fee imposed. Alternatively, a service could be delisted from the public benefit and therefore users of that service are required to pay for it out of pocket. A set of services could be delisted for only some populations (sectoral private financing). All of these forms of public rationing, along with the standard rationing through waiting, are at play across a variety of health care systems. As pressures on public budgets mount, along with the public appetite for transparency around public financing, these decisions play an increasingly important role and further scrutiny as to how they are made is justified.

The paper notes some important issues that are worth re-enforcing in the context of this type of examination. It recognizes that there are always going to be limits to what is provided publicly and that how individuals share in the responsibility for health care financing through private contributions will be important for system design, access, and equity. It recognizes that health care is but one input, and not the most important one, into good health, and that this must also be taken in account when considering how to allocate public resources. It recognizes that health care is not a homogenous commodity and that arguments in favour or against public provision of services will necessarily depend on what type of health care service is under consideration. Each of these points are important to keep in mind when considering how to define the publicly financed health care basket, and the role that private finance will therefore play within the system.

The paper's main contribution is to lay out a set of attributes which, taken together, provide a conceptual framework for exploring the suitability of private financing in a publicly funded health care system. The authors lay out six such attributes:

1. The concept of sufficient knowledge - that the considered health care service should enable individuals to value the need and quality both before and after utilization. Such goods and services would be those where the providers and patients have basically the same information set. Example services could include glasses, some drugs and assistive devices.

2. The concept of individual autonomy - that the considered health care service should be directed towards individuals with a reasonable level of individual 
autonomy. For the most part this would exclude individuals with limited cognitive abilities, patients requiring emergency treatment, patients being treated for addictive behaviours and children without proper adult decision makers.

3. The concept of public externalities - that the considered health care service should be associated with low levels of positive externalities. Services with a strong case for public financing based on merit, caring externalities, and/or large societal externalities would be excluded from this category.

4. The concept of sufficient demand - that the considered health care service should be associated with a demand of sufficient magnitude to generate a private market. Low market share, high cost items like expensive treatments for rare diseases where there is not sufficient market demand would presumably be excluded from this category.

5. The concept of affordability - that the considered health care service should be associated with payments affordable for most individuals. The authors note that by payments they mean direct out of pocket payments and not those items covered by private insurance, thereby eliminating most intensive treatments that require high levels of technology, and many patented pharmaceutical treatments.

6. The concept of lifestyle enhancement - that the considered health care service should be associated with lifestyle enhancements rather than medical necessities. Examples given of such treatments include cosmetic surgery, doping, or medication for erectile dysfunction, rather than procedures meant for 'pain avoidance' which are considered by the authors to be medically necessary.

While these attributes provide a workable conceptual framework for considering what should be left to the private domain, an alternative, and I would argue more integrated, approach would be to conceive of the problem the other way around and consider what is required for inclusion within a publicly funded health care system. Through a set of attributes, which could include medical necessity, cost-effectiveness, comprehensiveness of care, and consistency with the stated values of the jurisdiction, items would be considered for inclusion within the public basket, leaving those determined not appropriate for public coverage as necessarily part of the privately financed set of services (assuming that they meet some safety and/or quality standard). Re-conceiving of the problem in this way reveals a few challenges for public systems to overcome, as well as some flaws in the attributes presented by the authors for determining what is privately financed.

What flaws are revealed in attributes for consideration for private financing when the problem is viewed from the perspective of what is appropriate for public financing? One of the commonly used criteria for inclusion in the public system is cost effectiveness. Jurisdictions which use cost effectiveness evaluation to determine public inclusion may, understandably, reject items that have very high costs, limited use, and low expected benefit. Examples of this might include some very expensive pharmaceutical treatments. Many jurisdictions would then reasonably allow those individuals who wished to use these treatments (assuming, once again, that they are safe and effective even if not cost effective) to purchase 
them privately. These treatments are likely to be unaffordable for most people (therefore violating attribute five) and there is likely to be insufficient demand for a true 'market' for the drug that might produce, for example, insurance options (therefore violating attribute four). But if we consider items that are not publicly financed as left for the private market, these types of treatment would nonetheless qualify.

A second concern with the attributes for private inclusion presented above is the difficulty in defining the concept of lifestyle enhancement (attribute six). Some jurisdictions have recently gone through extensive debate about whether to include, for example, reproductive assistance in the publicly financed basket. Ontario, Canada, for example, recently announced that it would include one round of in vitro fertilization treatment in the publicly financed health service after many years of rejecting requests to fund such treatments even though these services are not strictly 'pain avoiding', narrowly defined. Reasons given for public financing of such services include improved access, safety, and opportunity for people who have lost the ability to conceive because of other health complications (Government of Ontario, 2014).

A third concern might be the implications of attribute one, sufficient knowledge, on the decision to exclude something from the publicly financed basket of services, and therefore include it in the privately financed basket. It is reasonable to assume that a number of services may fail typical requirements for public inclusion for reasons of information, cost, medical necessity, etc. that may also fail the attribute of being easily understood and monitored by individuals. Once again we are then left with the problem of how to handle such services once they have been rejected from the public basket. It seems overly restrictive to ban them altogether, and therefore they should be left for private consumption (perhaps with a buyerbeware warning).

Considering the problem of what to include in the basket of services from the perspective of the public funder also reveals a challenge for jurisdictions working to providing comprehensive care across a variety of providers and treatments in an ever changing technological environment. Some jurisdictions have relied heavily on sectoral distinctions in determining what is medically necessary. Canada, for example, continues to define medically necessary as those services provided by a doctor or in a hospital, leaving those items provided outside of those environments to be privately financed for many individuals. This set of criteria fails both any reasonable definition of medically necessary that includes medical need and cost-effectiveness, etc. (insulin, e.g., is not defined as medically necessary for diabetics for certain populations) as well as the criteria set out above for private financing.

How best, then, can jurisdictions both work towards maintaining an effective publicly financed basket of services that respects criteria of medical necessity and cost-effectiveness, while avoiding some of the pitfalls mentioned above? One model that shows promise (perhaps surprisingly for some) is the model outlined 
in the US Affordable Care Act (ACA). In considering what would be covered by the plans associated with the ACA, policy makers recognized that, while the health needs of a population remain relatively constant over time, changes in practices and technologies alter the best way of meeting these needs. For example, many chronic diseases that are treated by prescription medication today would have been treated in hospitals a few decades ago. With this in mind, the US legislators designed the ACA benefit package around the health needs themselves. They enumerated 10 categories of 'Essential Health Benefits'. These include familiar types of services (ambulatory, emergency, laboratory and hospital services) and supplies (including prescription drugs), but also mental health, substance use and behavioural health services; rehabilitative and habilitative services and devices; preventive and wellness services and chronic disease management; and pediatric oral and vision care (Glied and Stabile, 2012). The scope of services can be very broad and, unlike the Canadian example cited above, includes many services not traditionally provided by doctors and hospitals. Over time, government and insurance companies can adjust coverage to include those services that are best suited to treat particular health conditions, Of course, the issue of determining which services provide the most cost-effective way of treating a particular health need remains, but advances in technology assessment, pioneered by agencies like NICE in the United Kingdom offer workable solutions here too.

Given the continued challenge faced by many jurisdictions across the OECD to both control public health care costs and continually update the range of services provided by the publicly financed basket to reflect advancements in health care, a set of criteria that helps define what to include in the public basket may be more appropriate than focusing instead on what should be considered for private financing. Tinghog et al. (2010) clearly articulate many of the core issues in financing health care services, and provide a useful set of attributes for considering whether services are appropriate for private financing. They should be commended for this work. However, combining the lessons from the US Affordable Care Act on scope of care, the UK advances in technology assessment to determine cost-effectiveness as well as avoiding some of the mistakes that jurisdictions have made in letting history determine the publicly funded set of services, provides, in my view, a more promising path for an effective and sustainable publicly financed health service.

\section{References}

Glied, S., M. Stabile (2012), 'What Canada can learn from Obamacare', Toronto Globe and Mail, October 19. Available at http://www.theglobeandmail.com/globe-debate/whatcanada-can-learn-from-obamacare/article4621937/

Government of Ontario (2014), 'Improving access to safe fertility treatments', Ministry of Health and Long Term Care News Release, April 10. 
Stabile, M., S. Thomson, S. Allin, S. Boyle, R. Busse, K. Chevreul, G. Marchildon and E. Mossialos (2013), 'Containing health care costs in high-income countries: evidence from four nations', Health Affairs, 32(4): 643-652.

Tinghog, G., P. Carlsson and C. H. Lyttkens (2010), 'Individual responsibility for what? A conceptual framework for exploring the suitability of private financing in a publicly funded health-care system', Health Economics, Policy and Law, 5(2): $201-223$.

Thomson, S. and E. Mossialos (2009), Private Health Insurance in the European Union (DG Employment, Social Affairs and Equal Opportunities), Brussels: European Commission. 